\title{
Antiquity of Secluding Girls at Puberty
}

\author{
Abstract \\ In this article, it is pointed out that the seclusion of girls at puberty could have existed for more than \\ 40,000 years. The more likely mechanism of diffusion of the ideas around seclusion was the \\ migration of our ancestors not the cultural transmission itself. The customs of Australian Aboriginal \\ people provide a window into the past and some basis for fathoming the antiquity of the girls' \\ puberty rites.
}

\section{Introduction}

Seclusion of girls at puberty had been discussed by several authours including Frazer (1993), Benedict (1934) and Richards (1962). However, apart from Frazer, the other authours mainly looked at anthropological importance of this rite of passage. Arachige (2009) discussed the possible significance of these rites as a precursor to modern religions. Even though on its face value this may seem as a long shot, in a previous article Arachige (2010) suggested that there may be a link between the seclusion of girls at puberty and the Paleolithic Venus figurines. If this link is real then, finding the root of religion in the seclusion does not seem far-fetched. As a deduction independent of the antiquity of Venus Figurines, Arachige (2009) also hypothesised that the seclusion rites might have started at least 40,000 years ago. The present article makes a further case for the claim.

\section{Plausible Modes of Spread}

As Arachige $(2010,2011)$ pointed out, the seclusion of girls may take us to the prehistoric Europe. These rites had also been practised in many parts of the world. It is not unnatural to assign the reason for the spread of ideas of seclusion of girls around the world to a form of demic diffusion like of which helped the migratory population from the Middle East to carry their farming practices along to Europe. This mechanism of diffusion seems to be the more accepted way for the spread of farming to Europe from Middle East (Cavalli-Sforza, $2001)^{1}$. The idea of diffusion is in direct contrast to the view of independent development of customs and concepts proposed by Adolf Bastian in the nineteenth century. Proponents of the independent development view believe that there is a universal psychic unity of mankind which gives rise to "elementary ideas". This can perhaps lead to "archetypical concepts" such as spirits or reincarnation. However, I believe that this cannot be applied to a cultural practice like seclusion of girls at puberty as the puberty rites of girls are certainly a multitude of key ideas and events such as the first menstruation, need for seclusion including a shade, restricted movements, superstitions such as food taboos or mystical belefs about blood, not seeing males or not being seen by the males and later admittance to normal adult society. All these physical manifestations and mental constructs making the rites around seclusion of girls should come together in a synchronic and coherent structure, which then have to amount to a rather composite archetype. Why should these separate components come together as a universal? At present, there doesn't seem to have a reasonable explanation. Secondly, it is not easy to see why the ideas around seclusion of girls should be universals. All the cultures, whose members practised seclusion at one time or another, do not have to feel the same about first menstruation; some can be shameful while others rejoice in it as readiness, for example, toward betrothal. One tribe could have secluded the pubescent girl while another tribe could have paraded her around. Thus, if there can exist a unity of theme among all the apparent diversity, it is difficult to assume that these societies made certain choices from a set of all possibilities independently, resulting in a custom with certain similarities across many societies in many lands. Without argument, we have to accept the fact that there can be various nuances and variations, introduced in a diachronic manner as well as across various geographies and cultures,

${ }^{1}$ p101-103. Cavali-Sforza, Luigi L. (2001) 
to what originally was a pure form of a custom. This should be the case irrespective of the manner by which a culture acquired a certain practice. As Levi-Strauss pointed out,

Ethnographical observation does not,...,oblige us to choose between...either a plastic mind passively shaped by outside influences; or universal psychological laws that everywhere give rise to and invite the same properties regardless of history and of the particular environment ${ }^{2}$ "

Thus, there is no sound reason for us to exclude the possibility of diffusion of the practice of seclusion of girls at puberty even though there can be wide-ranging differences between various cultures around the same rudimentary set of ideas. As Levi-Strauss emphasises "each culture is a unique situation..".

As can be seen from the geographies which Sir James Frazer described in his book, The Golden Bough, with regard to the prevalence of girls' puberty rites and the elements common across many of these geographies, it is not impossible to believe that there had been a diffusion of these rites from some region. Given the prevalence of these rites in Africa, for an example, among Zulus ${ }^{3}$ and the San people ${ }^{4}$ whose Khoisan language ${ }^{5}$ is among southern African click languages, it is likely that these rites had an African origin. If we assume that the diffusion of cultural elements of seclusion took place along with the migratory trends of the ancient people, the ancestors of Australian Aborigines had to take it with them on their way to Australian continent at least 40,000 years ago. Genetically, Papua New Guineans are the closest to Australians (CavalliSforza 2001, p144) and thus, should be separated from the common ancestor more than 40,000 years ago (Zimmer 2001, p299; Cavalli-Sforza 2001, p169;Pettitt 2009, p128). The date based on Mungo man's remains is consensually about 40,000+/- 2,000 years and human presence in the Lake Mungo region is 50,000 to 46,000 years old ${ }^{6}$. Let us take the most recent consensus as the reference point for the settlement in Australia. How plausible is the diffusion through migration? Can it just be cultural diffusion which helped spread the seclusion of girls? Despite the fact that it is difficult to deduce the exact mechanism of diffusion, we investigate a few likely scenarios in next parts of this article.

\section{A more recent cultural acquisition?}

Given the prevalence of seclusion in Northern Territory, Torres Strait Islands, Cape York region, Papua New Guinea and New Ireland etc (Frazer 1993), one might assume that the seclusion at puberty have come to Australia from the northern neighbours in recent historical times ${ }^{7}$. It may be possible that the people who spoke Austronesian languages ${ }^{8}$ brought these rites to New Guinea and Oceania. New Guineans had Austronesian influence marked by the introduction of pigs, chicken etc around $1600 \mathrm{BC}^{9}$. Despite their innate suspicions, it is possible that various Aboriginal communities had exchanged goods and had other trade links over a long period of time ${ }^{10}$. Such exchanges might also have opened up opportunities for cultural contacts including the practice of puberty rites for girls. Around $500 \mathrm{AD}$, these rites might have gone westward to Madagascar with the Austronesian travellers and from there to continental Africa. However, it is difficult to imagine the influence of a band of travellers to Africa from the island of Madagascar to which Austronesian languages in African region are currently confined. In any case, this is a very unlikely scenario as diffusion of seclusion of girls was evident not only in Africa but also in Americas. More accepted view about spread of

\footnotetext{
2 p104. Levi-Strauss (1992)

3 p595. Frazer, J (1993)

${ }^{4}$ Lewis-Williams and Biesele (1978); Lewis-Williams (1980)

${ }^{5}$ Veeramah, Krishna. R. et al (2012) "We find substantial support for a model of an early divergence of KhoeSan ancestors from a proto-Pygmy-non-Pygmy NKs group 110 thousand years ago.."

${ }^{6}$ Bowler, James. M. et al (2003)

${ }^{7}$ People from South East Asia might have come to Australia bringing the dingo with them between 4000 to 3500 years ago (Clarke, 2003).

${ }^{8}$ Austronesian languages are supposed to have originated in southern China. Then, these languages spread to Taiwan through migration. p280 of Bellwood and Hiscock (2009).

${ }_{9}^{9}$ p347. Diamond (2005). According to p277 of Bellwood and Hiscock (2009) pigs were introduced around $1000 \mathrm{BC}$.

${ }_{10}$ p273. Bellwood and Hiscock (2009)
}

Copyright www.thelureofnoma.com 2012Page 2 
modern humans to America was through Bearing Strait about 15,000 to 35,000 years ago. Thus, a recent cultural exchange cannot explain the existence of puberty rites in various parts of the new world which were not known to have been colonized by people speaking Austronesian languages ${ }^{11}$, or in the primitive cultures like San culture in Africa.

\section{Lessons from Australia's first settlers}

Australian Aboriginal culture provides a very valuable window into early hunter gatherer societies as the Aboriginal people

"had a basically uninterrupted history. There are no signs of any sharp breaks in the economy and technology, no indications that outsiders might have disrupted local patterns of development ${ }^{12 " .}$

The same can be assumed to be true for their cultural history as cultural changes are not completely detached from technological and environmental changes. Thus, for our purpose, the Australian Aboriginal people can supply a wealth of information.

Havemeyer (1886) reported

".. if one turns from physical criteria to their manners and customs it is only to find fresh evidence of their isolation. While their neighbours, the Malays, Papuans and Polynesians, all cultivate the soil, and build substantial huts and houses, the Australian natives do neither. Pottery, common to Malays and Papuans, the bows and arrows of the latter, and the elaborate canoes of all three races, are unknown to the Australians ${ }^{13 \prime \prime}$.

Even though this is a dated statement, apart from Copeland Island in northern Australia where the archaeological site Barlambidj provided some evidence of pottery and glass, on archaeological evidence, the most of Australian continent seemed to have been in isolation from south Asia for almost all of its early existence (Bellwood and Hiscock, 2009) ${ }^{14}$. After the subsidence of the Greater Australian land bridges, in more recent times, the periodic visits of Macassans had a lasting influence on the Aboriginal people in Arnhem Land. The influence of these visitors had been woven into the Aboriginal cultural life in the parts of the land where those contacts prevailed. However, it is doubtful that these interactions and cultural integrations spread across the rest of the continent. Given Australia's cultural isolation, it is not unreasonable to assume that even though there had been Indonesian and Papuan influence in parts of Australian continent such as Arnhem Land and Cape York ,"these influences did not penetrate into the rest of the continent" (Aborigines in Australian Society, Encyclopaedia Britannica, 2001). For an example, absence of agriculture among Australian Aboriginal communities in the mainland Australia, despite having evidence of practice of agriculture by northern neighbours and people in some of Torres Strait Islands, doesn't lend support to the possibility of cultural diffusion through foreign contact. According to Clarke (2003),

"it was the combination of the adaptability [of] Aboriginal hunting and gathering lifestyle and the variable Australian climate, rather than lack of knowledge, that prohibited sedentary food-producing practices spreading south into mainland Australia ${ }^{15 "}$.

\footnotetext{
${ }^{11}$ Austronesian languages have only been traced back to Easter Islands.

12 p57. Gould (1969)

13 Havemeyer and Keller (1917) Kindle Locations 1677-1680.

${ }^{14}$ p275. Bellwood and Hiscock (2009)

15 p186. Clarke (2003)
} 
Even though agriculture or farming is different to a cultural practice like puberty rites, the hunter-gatherer lifestyle, the influence of geography and climate, and lack of assimilation between the tribes and their new contacts could have restricted the cultural transmission, too. There might have been other reasons as well.

Apart from the restrictions imposed by the rigid marriage system of Aboriginal people, another reason for such differences among Aboriginal tribes can perhaps be found in the following observation:

"The Australian Aborigines in their wild state are not only suspicious of treachery in their neighbours, but often have a superstitious terror of distant tribes, with whose existence they are only acquainted by report ${ }^{16,}$.

There are other reasons, such as the one described below, which also provide explanations. Among huntergatherers it was usually the woman who married outside her community. Thus, the transmission of cultural traits should have happened through such marriages. However, it is questionable that there had been enough critical mass for cultural traits coming from a distant community through maternal lines to be transmitted. This lack of opportunity for such traits to prevail could have arisen from the place of women in Aboriginal society in the pre-colonisation times. The standing of women among some Aboriginal tribes is evident from the following quote:

Mr. Howitt says, "these (south-eastern) aborigines, even while counting descent-that is, counting the class names - through the mother, never for a moment feel any doubt, according to my experience, that the children originate solely from the male parent, and only owe their infantine nurture to their mother." Mr. Howitt also quotes "the remark made to me in several cases, that a woman is only a nurse who takes care of a man's children for him ${ }^{17 " \prime}$.

In such a social environment, a cultural practice brought in by a woman through marriage could only have a very limited opportunity to spread. In general, cultural transmission would facilitate the ideas that (1) help solve environmental problems (2) can be easily memorised and processed by our brains and (3) are conducive to retain and understand variable and difficult ideas which are useful or important ${ }^{18}$. Assuming that the above categories of ideas really influence the transmission of cultural elements, it is difficult to place girls' puberty rites among them, especially, in a tribal society which in the historical times, seemed to have held women in low esteem.

\section{Belief of Reincarnation}

Especially, regarding the penetration of beliefs, we can have a look at the Aboriginal groups in Australia among whose beliefs there are well-documented local variations of interest. Among such local variations was the belief in reincarnation. The belief of perpetual reincarnation of the primal spirits as babies prevalent among Arunta and Kaitish could not be found among south-eastern tribes. ${ }^{19}$ With many Australian tribes, the child inherits the totem from the mother or the farther. But for Arunta and Kaitish, the child inherits the totem of the locality where mother became aware of the life of the child. Here, it is important to note that there are two types of totemic categories; social totemism and cult totemism. The above Arunta local totemism, which was also a conception totemism, is a cult totemism, usually having no impact on marriage classes ${ }^{20}$. Social totemism which was used to promote exogamy among Aboriginal Australians ${ }^{21}$ makes more sense with patrilineal or matrilineal inheritance. These Arunta beliefs, apart from their belief in the attachment of such

\footnotetext{
16 Brough Smyth. (1878)

17 in Chapter 11, Mr. Frazer's Theory of Totemism, Lang, Andrew (1905)

18 p246, Atran (2002)

19 "So far, however, I have not been able to find that the Dieri have the Arunta belief in the reincarnation of the ancestor, nor have I found any trace of it in the tribes of South-east Australia" in Chapter 7, Medicine men and Magic, Howitt (1904)

${ }^{20}$ p235-238. Berndt and Berndt (1988)

${ }^{21}$ p6. Freud (1918)
} 
reincarnating spirits to certain haunted stones, were also shared by the tribes in the north and centre. The Euahlayi tribe from north-western New South Wales, with views about spirits not of primal origin, believed in a reincarnation of the uninitiated who died young ${ }^{22}$. Arunta belief system consisting of the acceptance of reincarnation and non-inherited totem was considered by Andrew Lang to be socially more advanced than that of south eastern Aborigines ${ }^{23}$. Sir James Frazer, without discriminating between cult and social totemism, had the totally opposite view about the Arunta practices:

"This [Arunta] mode of determining the totem has all the appearance of extreme antiquity. For it ignores altogether the intercourse of the sexes as the cause of offspring, and further, it ignores the tie of blood on the maternal as well as the paternal side, substituting for it a purely local bond, since the members of a totem stock are merely those who gave the first sign of life in the womb at one or other of certain definite spots ${ }^{24 "}$.

Not being an anthropologist, it is not my preference to be judgemental. However, if we pay some attention to the fact that migration of first Australians occurred while the Australian continent had been joined to the Asian neighbours via land bridges which were severed about $9600 \mathrm{BC}^{25}$, it would be easy to conceive the antiquity of the central tribes. As the migrants arrived in to the mainland from Australia's northern neighbours, perhaps, via East Timor, it is very likely that the ancestors of Aboriginal people first came to the northern parts of the continent. They are also believed to have reached western parts of Australia around $50,000-46,000^{26}$ years ago. Then, with a high likelihood, they had to migrate towards the centre to be around Lake Mungo area by 40,000 years ago. Given the nature of their geographic location, the central tribes had a little chance to absorb the influences arising from possible exogenous contacts such as the northern tribes influenced by Asian neighbours or the Cape York tribes whose culture was modified by the New Guinean contact. Thus, it is very probable that Arunta represent a more primitive culture than the northern or coastal cultures. Another important fact about Arunta is their mythical tradition describing female ancestors who were frequently more powerful than the male figures ${ }^{27}$. Tribes in the Great Victorian Desert and the Arnhem Land had similar myths extolling more powerful female ancestors who had controlled the sacred rites. If the ideas of a prehistoric earth goddess and matrilineal descent as discussed by scholars such as J.J. Bachofen and Marija Gimbutas are believable and universal, then myths which we just discussed should point to an era before the dominance of the male in Aboriginal society. On the other hand, for our purpose, we don't need to find the most primitive tribe whose practices involved seclusion of girls at puberty. If the seclusion was widespread enough, in the relative absence of dominant cultural exchanges, it is very likely that it had a very long history. If Arunta were the followers of most ancient practices, then, they practicing seclusion of girls only vouch to the antiquity of the practice.

\section{Seclusion of girls among Aboriginal Australians}

Berndt \& Berndt (1988) discussed girls' puberty rites under "Initiation of Girls" in their highly regarded book The World of the First Australians.

\footnotetext{
22 "..the Euahlayi the spirits are new freshly created beings, not reincarnations of ancestral souls, as among the Arunta" in Chapter VII. Birth-Betrothal-An Aboriginal Girl from Infancy to Womanhood, Langloh Parker (1905)

${ }^{23}$ The south-eastern tribes .... socially less advanced than the Arunta, have not the Arunta nescience of the facts of procreation, a nescience which I regard as merely the consequence and corollary of the Arunta philosophy of reincarnation" Andrew Lang in the introduction to Langloh Parker (1905)

${ }^{24}$ Andrew Lang in the introduction to Langloh Parker (1905)

${ }^{25}$ p265. Bellwood and Hiscock (2009)

${ }^{26}$ Bowler, James. M. et al (2003)

27 p257. Berndt and Berndt (1988)
} 
"Speaking very generally, at the first sign of puberty a girl leaves the main camp, and spends several days in a little hut or shelter some distance away from it. She may have to observe certain food tabus at this time $e^{28 \prime \prime}$.

Berndt \& Berndt (1988) do not discern the difference between pure puberty rites such as seclusion from other forms of initiation rites such as cutting genitalia of girls and defloration by many men. For our purpose, we are only concerned about the rites involving seclusion ${ }^{29}$. Girls' puberty rites might have been subject to change over time. Thus, whatever reported by early ethnographers might be the remnants of much wider and elaborate practice. As we discussed earlier, Andrew Lang considered South Eastern tribes as more primitive. An early ethnographer, Howitt (1904), who wrote a book about south eastern tribes of Australia, didn't pay attention to female pubertal rites. There can be several reasons. What Hamilton (1987) wrote in a more recent context can still be relevant in a wider meaning too:

"What is apparent from Munn's account is that men have intruded in various ways into the realm of women's rituals. These are no longer exclusively and secretly a possession of women... 30 ".

Thus, Howitt (1904) might not have given much importance to these practices in south eastern tribes due to the fact that the male rituals dominated the Aboriginal life and the female rituals were held in conjunction with male rituals. These ethnographers might not have had direct contact with the native women who had more genuine knowledge about these rites and might have considered them or some of them as sacred secrets.

On the other hand, the puberty rites that the early ethnographers reported might have retained all the basic characteristics without much change from their prehistoric origins. Spencer and Gillen (1899) reported seclusion of girls among Central Australian Aborigines. Earlier, we considered Frazer's point of view according to which Arunta subscribed to a more primitive belief system. If that is the case, the following practice of seclusion of girls among Arunta should be a more primitive or as primitive as the customs practised by other tribes.

"In the Arunta and Ilpirra tribes a girl at the first time of menstruation is taken by her mother to a spot close to, but apart from, the Erlukwirra or women's camp, near to which no man ever goes. A fire is made and a camp formed by the mother, the girl being told to dig a hole about a foot or eighteen inches deep, over which she sits attended by her own and some other tribal Mia, who provide her with food, one or other of them being always with her, and sleeping by her side at night time. No children of either sex are allowed to go near to her or to speak to her. During the first two days she is supposed to sit over the hole without stirring away; after that she may be taken out by one or other of the old women hunting for food. When the flow ceases she is told to fill in the hole. She now becomes what is called Wunpa, returns to the women's camp, and shortly afterwards undergoes the rite of Atnaariltha $^{31}$, and is handed over to the man to whom she has been allotted. She remains Wunpa until such time as her breasts assume the pendent form so characteristic of the native women who have

\footnotetext{
${ }_{28}^{28}$ p180. Berndt and Berndt (1988)

${ }^{29}$ However, it is accepted that counting the seclusion among initiation rites is the more appropriate treatment. Just for the topic of the present article, it was thought to view seclusion in isolation for the ease of grasping the contextual basis.

${ }^{30}$ p47. Hamilton (1987). This comment is about the ceremonies of Walbiri women which previously performed along endogamous moieties had apparently changed over a period of twenty years to be performed by women related via a male. ${ }^{31}$ It is interesting to note that, according to Spencer and Gillen (1899), Aboriginal myths linked this practice to subincision of men. They also discussed the custom of 'promoting the growth of the breasts' under "MEN PAINTING THE BREASTS OF A GIRL WITH FAT AND RED OCHRE AFTER CHARMING IT - TO BE REGARDED AS A CEREMONY OF INITIATION". Taken together these two customs of stimulating the growth of breasts and the Atna-ariltha, we can speculate that had Arunta had the required skills and had they had imagined capturing them in three-dimension, they would have symbolically represented these two features as big breasts and prominently displayed pubic triangles of Paleolithic Venuses.
} 
borne one or more children, after which she is spoken of as Arakutja, the name for a fully-grown woman $^{32 "}$.

This cultural practice might have existed in a similarly veiled form in other parts of the land as the following account by Langloh Parker about the Euahlayi Tribe of north western New South Wales reminds us:

"A girl's initiation into womanhood is as follows. Her granny probably, or some old woman relation, takes her from the big camp into the scrub where they make a bough shade. As soon as this is made, the old woman sets fire to a thick heap of Budtha leaves and makes the girl swallow the smoke. She then bids her lie down in a scooped-out hollow she has made in the earth, saying to her, 'You are to be made a young woman now. No more must you run about as you please. Here must you stay with me, doing as I say. Then in two moons' time you shall go and claim your husband, to do for ever what he bids you. You must not sleep as you lie there in the day time, nor must you go to sleep at night until those in the camp are at rest. I will put food ready for you. Honey you must not eat again for four moons. At first streak of day you must get up, and eat the food I have placed for you........

Girls have told me that they got very tired of being away with only the old woman for so long, and were glad enough when she told them they were to move to a new camp, nearer to the big one, which the women had prepared for them ${ }^{33 \prime \prime}$.

Note that the last paragraph of the above quote. Such inconveniences might have resulted in changes to the original form of pubertal rites.

According to Frazer in The Balder the Beautiful, in Cape York Peninsular area, tribes such as Otati, the tribal people in the western part of Cape York Peninsula and Kia people in eastern Queensland dig a hole or a pit for girls at first menstruation to spend time away from the camp ${ }^{34}$. Uiyumkwi tribe in Red Island, an island of Torres Strait, would keep the girl at her first menstruation in a shallow trench dug in the foreshore. Thus in essence, many Aboriginal groups, including Arunta and Euahlayi, follow the same basic structure and pattern of responding to puberty. These tribes would seclude the girl, keep in a hollow dug in the ground and provide a temporary shade. Sitting in a hole dug in the ground restrict the girl's movement. The aboriginal people of the Pennefather River area in the Cape York make the girl sit cross legged while Uiyumkwi girl, as mentioned, lies at full length in the trench. This simply exemplifies the possibility of variations around a fundamental theme among different tribes. Confining the girl to a hole or trench is restricting her movement which the rule of "not to touch the ground" with her feet symbolically achieve ${ }^{35}$. If someone has no feet, that person should be carried around, crawl or stay put. Similarly, if someone is allowed to walk only upon something covering the ground or permitted to walk only without touching the earth; i.e. wearing bark sandals ${ }^{36}$, then, the freedom of movement would suffer. All these scenarios can only result in restricting the movement of the subject.

Seclusion in a temporary shade covers the girl from sun in a symbolic gesture and make sure she is not seen by others. Thus, we can still see the elementary manifestation of rules, not seeing the sun and not touching the ground which might have been what the migrants brought with their ancestral roots. On the other hand, these rudimentary manifestations might have also been a result of a cultural adaptation influenced by geographical and climatic realities of the Australian landscape. It is also possible that, in prehistoric times, the seclusion of girls which had been practised in more elaborate form, had vanished later from cultural memory due to the influence of overbearing male initiation rites which had even absorbed some elements of female ceremonies

\footnotetext{
${ }^{32}$ Chapter 12 , Spencer and Gillen (1899)

${ }^{33}$ Langloh Parker (1905)

${ }^{34}$ Frazer, J. G. in The Balder the Beautiful (Seclusion of girls at puberty in Nothern Australia)

${ }^{35}$ Another way to restrict movement in some societies was to introduce a piece of iron which had to be carried wherever the girl went. In the past, Sri Lankan and South Indian puberty rites dictated such a practice. Another way to restrict movement is to prohibit someone to be alone (see Arachige 2010).

${ }^{36}$ According to p27 of Gould (1969), the Aboriginal women of Gibson Desert used to make bark sandals even in recent times. The point considered here is that the possibility of wearing such sandals by girls at puberty could have been a practice which
} was later abandoned and history never recorded. 
and the dominance of males in general. Given the accounts in the published material near the dawn of last century, the initiation of boys had a far greater influence in their culture (Spencer and Gillen $2009^{37}$; Havemeyer 1886). Revealing the secrets of boys' initiation to women was a punishable offence for South Eastern tribes (Howitt 1904). In essence, it is difficult to determine whether these rites were handed down to recent generations in a form, which was closer to the original or was transformed by the local conditions and cultural constraints to a conformal practice.

\section{Conclusion}

It is not unreasonable to assume that the girls' puberty rites diffused across vast spaces of land with the migration of our ancestors. Seclusion of girls at puberty is very likely to have reached various parts of Australia with the arrival of ancestors of Australian Aboriginal people at least 40,000 years ago. Among Australian Aboriginal people, the puberty rites had become part of broader initiation of girls. These rites might have changed over the long history of Aboriginal people. However far back into the past the Aboriginal customs would relate to, the seclusion at puberty, at least, until the times of European encounters, retained many structural elements from the broader practice as described by Sir James Frazer in his monumental work The Golden Bough. Thus, to reach Australia, at least 40,000 years ago, these rites should have started their journey long before. With such an antiquity it is not unlikely that the girls' puberty rites existed while Paleolithic Europe experienced its creative explosion.

\section{References}

Arachige, D. (2009) The lure of noma: on the elegance of religion, Perth: Ocean Publishing Arachige, D. (2010) Prehistoric Venuses and Puberty Rite, http://www.thelureofnoma.com Arachige, D. (2011) Witches, Shamans and Girls at Puberty, http://www.thelureofnoma.com Atran, Scott (2002) In Gods we trust: The evolutionary landscape of religion, Oxford University Press, New York Bellwood, Peter and Peter Hiscock (2009) Holocene Australia and the pacific basin in The Human Past ed. by Chris Scarre, Thames \& Hudson, London Benedict, R. 2005 (1934) The patterns of culture, Mariner Books: New York Berndt, Ronald. M. and Catherine H. Berndt (1988) The world of the first Australians: Aboriginal Traditional Life: Past and Present, Aboriginal Studies Press, Canberra

Bowler, James. M. et al (2003) New ages for human occupation and climatic change at Lake Mungo, Australia. Nature 421:837-40. doi:10.1038/nature01383

Brough Smyth, R. (1878) The Aborigines of Victoria, Vol II, Government Printer, London- available at http://books.google.com/

Cavali-Sforza, Luigi L. (2001) Genes, Peoples \& Languages, Penguin

Clarke, Paul (2003) Where the ancestors walked, Allen \& Unwin, Crows Nest, NSW

Diamond, Jared (2005) Guns, Germs and Steel, Vintage

Frazer, James (1993) The golden bough: A study in magic and religion, Ware: Wordsworth Reference

Freud, Sigmund (1918) Totem and Taboo, Moffat, Yard and Company, New York - available at

http://books.google.com/

Gould, Richard. A. (1969) Yiwara, Foragers of the Australian Desert, Chrles Scribner's Sons, New York Hamilton, Annette (1987) Dual Social System: Technology, Labour and Womens' Secret Rites in the Eastern Western Australia in Traditional Aboriginal Society: A Reader ed. by W.H. Edwards, The Macmillan Company of Australia, Melbourne

Havemeyer, Loomis and Albert Galloway Keller (1917) Ethnography; a partial and preliminary description of the races of man, Press of the Wilson H. Lee Company, New Haven, Conn Kindle edition available at www.archive.org/

Howitt, A. W. (1904) The Native Tribes of South-East Australia, Macmillan \& Co Ltd, London available at books.google.com.au

${ }^{37}$ Chapters 7, 8 and 9 of Spencer and Gillen (1899) 
Lang, Andrew (1905) The Secret of The Totem, Longmans, Green \& Co, London- available at http://books.google.com/

Langloh Parker, K. (1905) The Euahlayi Tribe: A Study of Aboriginal Life in Australia, online at www.gutenberg.net

Levi-Strauss, Claude (1992) Structuralism and Echology in The view from afar, The University of Chicago Press, USA

Lewis-Williams, J. D and M. Biesele (1978) Eland hunting rituals among northern and southern San groups: striking similarities, Africa, 48 (2):117-134

Lewis-Williams, J. D 1980. Remarks on Southern San Religion and Art, Religion in South Africa, Vol.1 (2):19-32 Richards, A. I. (1982) Chisungu: A Girl's Initiation Ceremony among the Bemba of Zambia, Routledge, London Pettitt, Paul (2009) The Rise of Modern Humans in The Human Past ed. by Chris Scarre, Thames \& Hudson, London

Spencer, Baldwin and F.J. Gillen (1899) The native Tribes of Central Australia, Macmillan, London; Retrieved from http://ebooks.adelaide.edu.au/s/spencer/baldwin/s74n/

Veeramah, Krishna R. et al (2012) An Early Divergence of KhoeSan Ancestors from Those of Other Modern Humans Is Supported by an ABC-Based Analysis of Autosomal Resequencing Data, Mol Biol Evol (2012) 29 (2): 617-630. doi: 10.1093/molbev/msr212

Referencing this article:

Arachige, D. 2012, Antiquity of Secluding Girls at Puberty, http://www.thelureofnoma.com

This article can be copied and distributed as it appears above, inclusive of the copyright warnings. 